\title{
A METHOD FOR PREPARING REMAINS OF CLADOCERA (CRUSTACEA) AND CHIRONOMID (DIPTERA: INSECTA) FOR SCANNING ELECTRON MICROSCOPY
}

\author{
ANDRADE-MORRAYE, M., ${ }^{1}$ ESKINAZI-SANT'ANNA, E. M. ${ }^{2}$ and ROCHA, O. ${ }^{3}$ \\ ${ }^{1}$ Departamento de Ecologia e Biologia Evolutiva, DEBE, Universidade Federal de São Carlos, SP, C.P. 676, \\ CEP 13565-905, Brazil \\ ${ }^{2}$ Departamento de Oceanografia e Limnologia, Universidade Federal do Rio Grande do Norte, Via Costeira, \\ s/n, Praia de Mãe Luiza, CEP 59014-100, Brazil \\ ${ }^{3}$ Laboratório de Limnologia, Departamento de Ecologia e Biologia Evolutiva, DEBE, Universidade Federal de São \\ Carlos, SP, C.P. 676, CEP 13565-905, Brazil \\ Correspondence to: Mônica Andrade-Morraye, Departamento de Ecologia e Biologia Evolutiva, DEBE, Universi- \\ dade Federal de São Carlos, SP, C.P. 676, CEP 13565-905, Brazil, e-mail: monica@morraye.net \\ Received January 15, 2004 - Accepted January 28, 2004 - Distributed November 30, 2004
}

(With 3 figures)

Most methods used for preparing remains of Crustacea and Insecta for scanning electronic microscopy (SEM) were designed ideally for entire organisms. The method here presented was adapted from previously existing methods (Feugenhouer, 1987) and constitutes a practical procedure to work with fossil invertebrate remains.

\section{Description of the proposed method}

Sediment samples containing Chironomidae and Cladocera remains must be previously treated following the procedure of Frey (1986), which consists of sample deflocculation in hot $10 \% \mathrm{KOH}$ (or $5 \% \mathrm{NaOH}$ ). After that, the material is washed and sieved through a $25 \mu \mathrm{m}$ screen in order to avoid losses of Cladocera head shields. The material is then very carefully transferred to a small glass recipient, using distilled water to wash the sieve. If the material is to be processed within few days, no need exists to preserve it. Otherwise the material should be preserved with $4 \%$ formaldehyde or $70 \%$ alcohol.

Chironomidae head capsules and Cladocera carapaces and head shields must be sorted under stereomicroscope, and the remains picked up with a needle or pipette and transferred to a small Petri dish. They must be washed with distillated water thrice, for 5 minutes each time, using a small nylon bag. (The nylon bag can be made by cutting a pipette pointer, introducing a piece of nylon big enough to cover the hole, and securing the nylon with a ring made from the pointer.)
The nylon bag containing the material is then introduced into a solution of $1 \%$ osmium tetroxide $\left(\mathrm{OsO}_{4}\right)$ for 2 hours. After that, the material should be washed with distilled water and then submitted to an ethanol dehydration sequence using the following concentrations: $25 \%, 50 \%, 70 \%, 80 \%, 90 \%, 95 \%$, and $100 \%$ for a period of 30 minutes each. After that the material should be left overnight (12 hours) on a glass-fiber filter (AP20) in order to dry under a high-intensity lamp.

The filters must then be fixed with commercial glue onto a stub (Fig. 1), which is an aluminum base, following the specificities of the particular Scanning Electron Microscope model. The material on the stub should be transferred to a vacuum desiccator to avoid dehydration, and then submitted to gold impregnation before scanning.

The analysis of the material at the SEM can be performed using a $15 \mathrm{kV}$ current intensity and a $15 \mathrm{~mm}$ distance between the sample and the electron beam.

Examples of the results that can be obtained using this methodology are shown in Figs. 2 and 3. The micrographs were obtained using two different equipment: a Zeiss SEM from the Electronic Microscopy Center (CEMEL) at the Institute of Biological Sciences of the Federal University of Minas Gerais, and a Phillips SEM from the Laboratory of Image Processing (LPI) in the Materials Engineering Department of the Federal University of São Carlos. These figures indicate the efficiency of the technique described. 

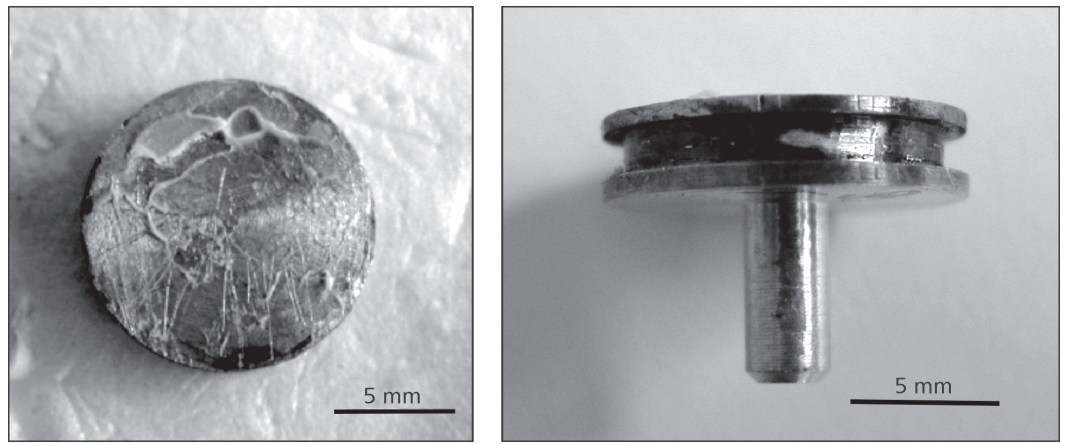

Fig. 1 - Upper and lateral view of the stub.
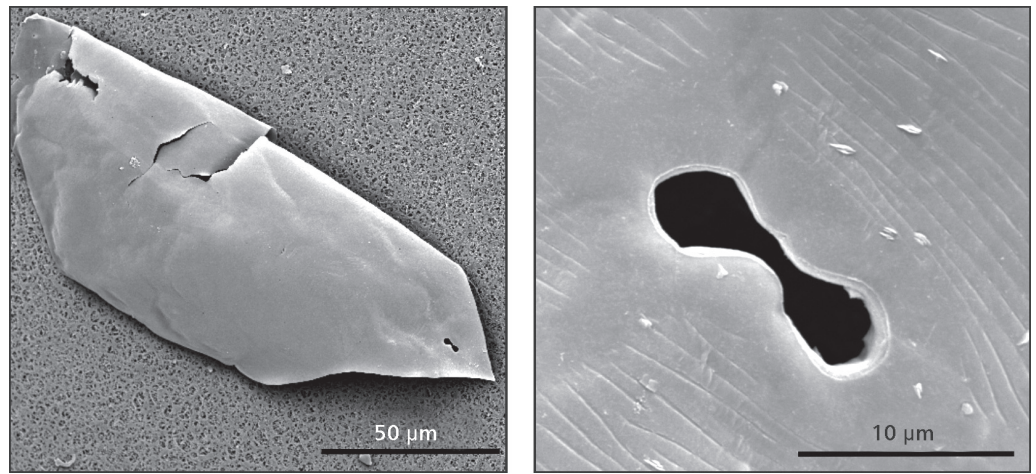

Fig. 2 - Micrographs of Alona affinis head shield with details of the head pores.

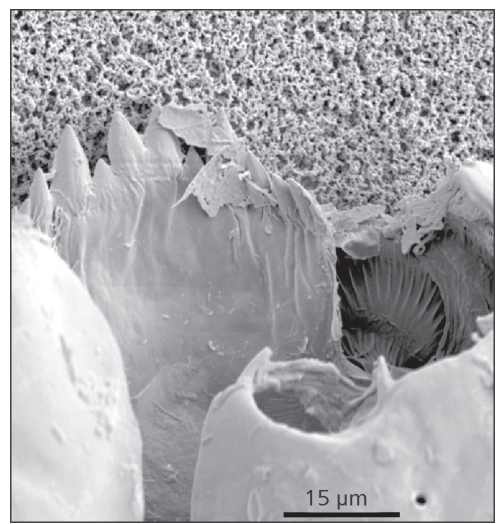

Fig. 3 - Micrograph of Polypedilum sp. head capsule.

The suggested and tested adaptations represent a simplification of SEM analysis methodology and an improvement in the previously existing process for preparation of biological materials. The method can improve taxonomic knowledge by facilitating the analysis of morphological characteristics of both microcrustaceans and insect remains.

\section{REFERENCES}

FELGENHAUER, B. E., 1987, Techniques of preparing crustaceans for SEM (scanning electron microscopy). Journal of Crustacean Biology, 7(1): 71-76.

FREY, D. G., 1986, Cladocera Analysis. In: B. E. Berlung (ed.), Handbook of Holocene Palaeoecology and Palaeohydrobiology. John Wiley \& Sons Ltd., pp. 667-693. 